\title{
\{ CARNADOCS \}, EXPLICANDO AS ENTRELINHAS
}

\author{
Izabel Maria de Oliveira \\ Professora adjunta do Departamento de Artes e Design da PUC-Rio. \\ Contato: izabel-design@puc-rio.br
}

\section{Nathália Valente Cramer Ribeiro}

Graduada em Design com habilitação em Comunicação Visual pela PUC-Rio.

Contato: nathaliavcramer@gmail.com

\author{
Nilton Gonçalves Gamba Junior \\ Coordenador do DHIS - Laboratório de Design de Histórias do Programa de Pós-graduação em \\ Design do Departamento de Artes e Design da PUC-Rio. \\ Contato: gambajunior@puc-rio.br
}

\section{RESUMO}

O artigo apresenta $\{$ carnadocs $\}$, um projeto de série audiovisual que difunde os quesitos de julgamento das escolas de samba do Rio de Janeiro em diálogo com o conceito de sustentabilidade comunicacional. O projeto analisa como o dinamismo dos sistemas multissensoriais contemporâneos podem preservar dados históricos, difundir informações sobre a contemporaneidade e propiciar uma processualidade que permita atualizações futuras, favorecendo sua repercussão histórica, financeira, cultural e social.

Palavras-chave: carnaval; Rio de Janeiro; critérios; avaliação; audiovisual.

\section{$\{$ carnadocs $\}$, explaining between the lines}

\begin{abstract}
The aim of this paper is to present an audiovisual project, named $\{$ carnadocs $\}$, which tries to focus on the evaluation criteria of samba schools in Rio de Janeiro in dialogue with the concept of communicational sustainability. The project analyzes how the dynamism of contemporary multisensory systems can maintain historical data, disseminate information about contemporaneity and provide a process that allows for future updates, favoring their historical, financial, cultural and social repercussions.
\end{abstract}

Keywords: carnival; Rio de Janeiro; criteria; evaluation; audiovisual. 


\section{Introdução}

O projeto audiovisual $\{$ carnadocs $\}$ parte de uma premissa: a relevância atual das questões que envolvem a sustentabilidade social dos eventos de cultura popular. No âmbito da sustentabilidade sociocultural, destacamos a importância da comunicação como forma de difundir a representação das manifestações de cultura popular e rever seus estigmas.

Esse recorte de observação sugeriu o termo "sustentabilidade comunicacional", abordado no artigo homônimo (GAMBA JUNIOR e SARMENTO, 2019). A sustentabilidade comunicacional reflete a lógica mais ampla da noção de sustentabilidade para um diálogo com as especificidades do estudo da produção de sentidos na cultura. O conceito remete a termos mais tradicionais, como "poluição visual", ou mais contemporâneos, como "cultura tóxica", e serve de provocação a partir de perguntas como: "A comunicação poderia poluir, intoxicar, falir e prejudicar processos ou sociedades?" (GAMBA JUNIOR e SARMENTO, 2019, p. 1). São questionamentos que remetem a noções típicas da sustentabilidade ambiental ou econômica, mas que servem para dar visibilidade a questões no âmbito da cultura, como a toxicidade de conteúdos massivos na contemporaneidade.

Essa é uma reflexão que insere a pesquisa em Design na dimensão cultural da lógica sustentável, consolidando os nexos entre a área de Comunicação Visual e a produção cultural. Estudos sobre a produção estética dentro da área do Design implicam a cultura diretamente, logo, somam-se à relevância que o Design tem assumido nos esforços contemporâneos de uma lógica coletiva e sustentável. Isto é, considerando sua influência atual, é mais visível nos âmbitos da ecologia e economia e, portanto, mais relacionada às subáreas de Produto e Serviços. Nessa abordagem, a subárea de Comunicação Visual, ou Comunicação Multissensorial, se implica diretamente na sustentabilidade pelo seu aspecto social, especialmente no que diz respeito à sua aplicação nos estudos sobre culturas locais. $O$ projeto $\{$ carnadocs $\}$ parte desse conceito para apresentar uma intervenção com um recorte particular: os desfiles de escolas de samba do carnaval do Rio de Janeiro.

Como os desfiles de Escolas de Samba se situam em um universo que já aborda a linguagem audiovisual - imagem, música e textos -, não existiria uma atuação plena se não se mantivessem os mesmos recursos ao projetar nesse meio. A série audiovisual \{ carnadocs $\}$ tem como propósito informar sobre os quesitos de julgamento das escolas, buscando aprofundar o conhecimento de quem já se interessa e instigar aqueles que não os conhecem. Além disso, demonstra, por meio de uma "viagem pela história", a importância do Carnaval, combatendo diretamente o discurso negativo utilizado massivamente pelas igrejas (AFP, 2020) - em sua maioria, neopentecostais. Através do aproveitamento dessas estruturas dos quesitos, propõe-se legitimar a existência dessa avaliação, desqualificando um discurso simplista de "prêmio comprado" e valorizando a participação do componente e folião.

A partir de eixos temáticos definidos, abordamos a temática de uma forma descontraída e leve, voltando-a para o público jovem-adulto e adulto para que se conectem com a compreensão de uma estrutura de enredo já apresentada na avenida. Além disso, o projeto toma como parâmetros principais ser totalmente digital, não preferenciar nenhuma escola de samba específica e apresentar clareza e diversidade na linguagem utilizada.

\section{Contextualização}

Os desfiles das atuais agremiações se originaram como grupos de sambistas de terreiros que representavam suas inserções locais na cidade - ou seja, associavam suas manifestações aos bairros onde viviam. Nascidas por volta de 1920 no bairro Estácio de Sá, no Rio de Janeiro, logo se espalharam por vários subúrbios, especialmente nos morros. Popularmente é relatado que essas pessoas "desciam o morro" e iam à Praça Onze, onde ocorriam as evoluções e cantavam os sambas.

$\mathrm{Na}$ época, as fantasias usadas eram simples: baianas, homens com pijamas de listras, macacões e camisas de malandro somados a um chapéu de palha. De acordo com Luiz Antonio Simas e Fábio Fabato (2015), somente com o tempo começaram a se organizar e definir que cada escola teria um enredo. Com a oficialização do Carnaval, em 1938, foi regulamentado o desfile das escolas de samba que, entre outros requisitos, passaram a ser obrigadas a ter enredos sobre temas nacionais. Só então os sambas passaram a assumir uma temática específica e referir-se ao enredo. No entanto, os sambas ainda não eram gravados nem editados, apenas executados e cantados durante os desfiles.

Com os anos, os nomes dos grupos, número de escolas e regras de competição foram se modificando. Hoje, cada escola tem seus componentes divididos em alas, com a mesma fantasia de acordo com o enredo. São elas: uma bateria, uma

Revista online do Departamento de Arquitetura e Urbanismo da Pontifícia Universidade Católica do Rio de Janeiro - PUC-Rio, Brasil Ano 8 - No 9 - ISSN 2446-7340 
ala de baianas, por vezes ala de crianças, uma comissão de frente, casais de mestre-sala e porta-bandeira, e intérprete do samba enredo.

Os grupos são subdivididos em: Grupo Especial e Grupo de Acesso Série A, que desfilam no Sambódromo da Marquês de Sapucaí, e Grupos de Acesso Série B, C, D e E, que desfilam na Estrada Intendente Magalhães, ${ }^{2}$ onde são montadas arquibancadas para o público. O tempo mínimo de desfile é de 65 minutos e o limite máximo é de 75 minutos.

No percurso histórico das agremiações, são determinantes os vínculos que se estabelecem entre os desfiles e a indústria cultural. Primeiro, através do papel motor da imprensa radiofônica e impressa nas primeiras décadas do século $\mathrm{XX}$ e, depois, com o papel da televisão a partir dos anos 1950. Essas relações se reconfiguraram a partir da mudança de vários aspectos estruturais, como a presença de patrocínios privados, regulamentação e controle do Estado, relações com sistemas de contravenção, modelos de cadeia produtiva e estruturas de trabalho, dentre outros. As relações com a transmissão pela mídia hegemônica se tornaram fundamentais nessas reconfigurações.

A emissora de TV é hoje um dos principais controles da manifestação, sendo um dos maiores capitais de financiamento do desfile pelo atravessamento dos anunciantes até a determinação técnica ou estética, como as características de iluminação ou da cor da passarela, pensados mais para o processo de teletransmissão do que para a experiência local presencial.

Assim, podemos identificar como a influência das mídias de comunicação veio a interferir no rito e nas suas adaptações ao longo do tempo - uma justificativa para o recorte com abordagem da sustentabilidade neste estudo. Representação, mediação e difusão passam a interferir diretamente na expressão popular.

A comunicação dos desfiles e sua interferência na sustentabilidade do evento envolve inúmeros aspectos que demandam enfrentamentos distintos, como abordagem de projeto e pesquisa. Por isso, mais um recorte se inscreve no \{ carnadocs \} ao abordar especificamente os quesitos de julgamento das escolas e o seu conhecimento pelo público dos desfiles. Os quesitos de julgamento são um lócus de concentração de vários aspectos definitivos da expressão estética do evento e de sua comunicação com a audiência. Ainda assim, muitas dúvidas se mantêm pela falta de dados públicos: Quais as categorias de análise e os parâmetros limitantes de uma alegoria ou de um casal de mestre-sala e porta-bandeira? O que determina as configurações estruturais de uma ala de baianas? Como uma bateria pode inovar e até onde vão as caraterísticas que não podem, pelo estatuto, ser alteradas?

Para o desenvolvimento deste projeto, tomamos como partido que a difusão de informações técnicas sobre o festejo possa tornar a vivência da experiência do espetáculo mais articulada. Assim, a própria sociedade pode ter em mãos o poder de avaliar os aspectos que ainda são sectários e herméticos - na medida que são restritos a setores específicos, como os jornalistas especializados ou o próprio júri.

A difusão precária do conhecimento indica ainda um problema político presente na história dos desfiles que diz respeito também a uma questão de classes. A gradual alocação de práticas especializadas nas mãos de determinados setores da sociedade indicaram, no decorrer da história, uma elitização do controle cultural do festejo, como por exemplo: carnavalescos oriundos de escolas de Belas Artes e membros de classes altas, estudiosos e críticos especializados provenientes da burguesia, fora do contexto geopolítico das agremiações, e celebridades de outras naturalidades e até nacionalidades que se integram aos desfiles em posições como madrinhas de bateria ou destaques de carros alegóricos. Há também um movimento paralelo e lento de resistência, como o fomento à participação de especialistas, carnavalescos e destaques performativos locais, que tem sido importante para resgatar no desfile sua dimensão local e de classe.

Se a sustentabilidade social dos desfiles de escolas de samba envolve tão diretamente a democratização de algumas de suas funções e de vários dos conhecimentos envolvidos na sua produção, a visibilidade social dos quesitos e a divulgação de seus percursos históricos, seus marcos referenciais e seu funcionamento operacional, serão fundamentais nesse sentido.

Assim, o projeto $\{$ carnadocs $\}$ perspectiva a colaboração com a sustentabilidade comunicacional do desfile de agremiações carnavalescas no Rio de Janeiro destacando alguns pontos fundamentais: 1) Pesquisa e seleção de conteúdo, como etapa determinante para produzir alternativas às abordagens existentes; 2) Identidade Visual, criando um sistema de identificação dos diversos módulos do conteúdo, mas também comunicando com seus elementos questões relevantes para a sustentabilidade social do evento; e 3) Seriação e produção colaborativa, que vai permitir a viabilização do

Revista online do Departamento de Arquitetura e Urbanismo da 
projeto com redes de parcerias e mais autonomia em relação aos modelos hegemônicos de produção.

\section{Descrição e Etapas do projeto}

O projeto da série de vídeos tem como foco os quesitos julgados pela Liga Independente das Escolas de Samba do Rio de Janeiro (LIESA) e se compõe de: pesquisa e levantamento de informações, curadoria e roteirização de conteúdo textual e visual, gravação de narração, desenvolvimento da identidade visual (logotipo, ilustrações e itens de motion graphics), além da criação de um manual com parâmetros e diretrizes para reprodutibilidade da linguagem gráfica e produção dos vídeos.

A série foi dividida em 16 módulos temáticos que abordam: vertentes narrativas sobre o surgimento do Carnaval e sua etimologia, evolução das manifestações, surgimento das Escolas de Samba e do Sambódromo, LIESA e sua importância, organização e regras, quesitos (introdutório e mais generalista em todos), comissão de frente, bateria, enredo, samba-enredo, harmonia, evolução, alegorias e adereços, fantasias, mestre-sala e porta-bandeira e outros elementos.

Na pesquisa a respeito de projetos mais conhecidos sobre Carnaval, encontramos expressões como: Carnavalesco, Carnavalize, Carnafolia, entre outras. Percebendo um padrão do prefixo carna - e sua ligação direta com o nome da festividade -, o associamos com a sigla de uma série de documentários. Assim surgiu o nome $\{$ carnadocs $\}$.

\section{Pesquisa e seleção de conteúdo}

Levantar conteúdos em diversas plataformas e delinear eixos temáticos para os módulos foi importante, mas produzir a estrutura de roteiro a partir de Moss (1998) foi essencial, delimitando espaços para lidar com categorias diferentes de informação. Com a confirmação do adiamento e, depois, o cancelamento dos desfiles de 2021, a base para a definição de conteúdos foi o acervo de filmagens do Carnaval 2020. Para uma seleção justa de quais escolas seriam contempladas, adotamos como parâmetro as próprias notas dadas pelo júri. Sendo assim, todas as escolas que ganharam no mínimo quatro notas "10" em cada quesito estariam aptas para aparecer no vídeo correspondente ao quesito.

Para a edição final do material selecionado, foi fundamental a gravação do áudio - concebido no roteiro como um voice over - para compreender a tônica dos vídeos e entender e trabalhar as adaptações textuais necessárias à fala.

\section{Identidade Visual e Aplicações}

Para o desenvolvimento da identidade visual, elencamos uma série de diretrizes, como: representar a diversidade, a diversão e a descontração do carnaval; ser intensamente colorida para dialogar com a estética da manifestação; competir visualmente no atual contexto de excesso de informação e direcionar para o público jovem-adulto; usar estruturas gráficas com tons bem saturados e sem texturas para se distinguir mais facilmente das imagens de vídeo de apoio dos desfiles - geralmente excessivamente texturizadas e complexas em termos de elementos simultâneos de representação. Com base nesses conceitos, os estudos iniciais foram feitos com variações dentro de uma mesma família tipográfica, explorando suas multiplicidades. Depois de várias alternativas estudadas, optamos por trabalhar com diferentes tipografias. Como símbolo, usamos as chaves, presentes também no logotipo, que representam a abertura e fechamento do desfile na avenida.

Nos estudos de cor, levamos em consideração o parâmetro de não privilegiar nenhuma escola de samba. O sistema de cor RGB, padrão usado nas plataformas digitais, traz a possibilidade de trabalhar com uma gama de cores com luminosidades e saturações específicas que em trabalhos impressos causariam um custo elevado. Observando as tendências do Carnaval de 2020, adotamos cores de efeito flúor, como visto, por exemplo, em algumas fantasias do desfile da Portela. $^{3}$

Na vinheta de abertura dos vídeos, as letras surgem na tela dançando, remetendo ao movimento de rostos e corpos dos componentes da escola. No final, ela aparece estática, como se aguardasse ser fotografada. O fundo branco, muito importante para um respiro visual, está presente em todos os trechos dos vídeos e foi suporte para aplicação da tipografia. ${ }^{4}$

Para o desenvolvimento das ilustrações, partimos de estudos com fotografia, passando por ilustrações lineares no software mapa de bits, até chegarmos na linguagem vetorial,

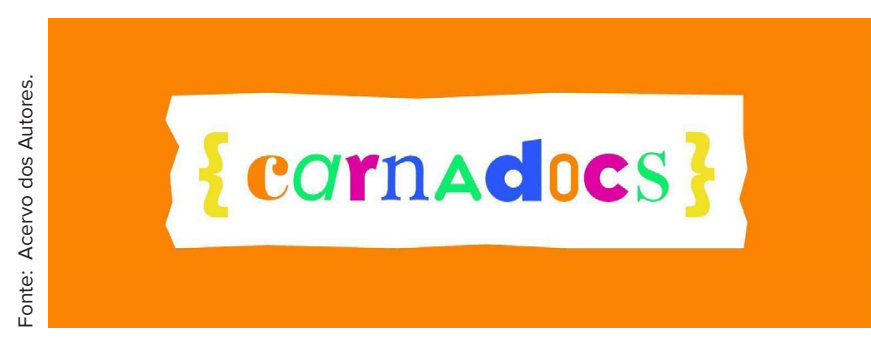

Figura 1. Logotipo em aplicação de fundo de cor utilizado no YouTube, 2020 


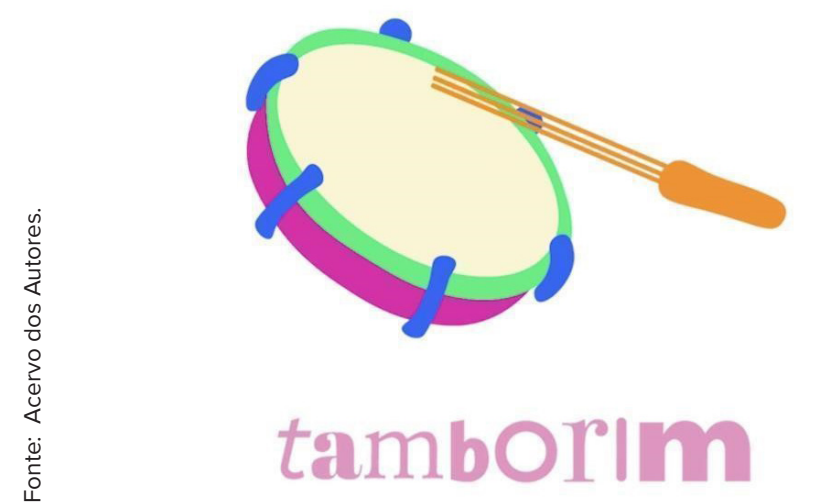

Figura 2. Uso de ilustração.

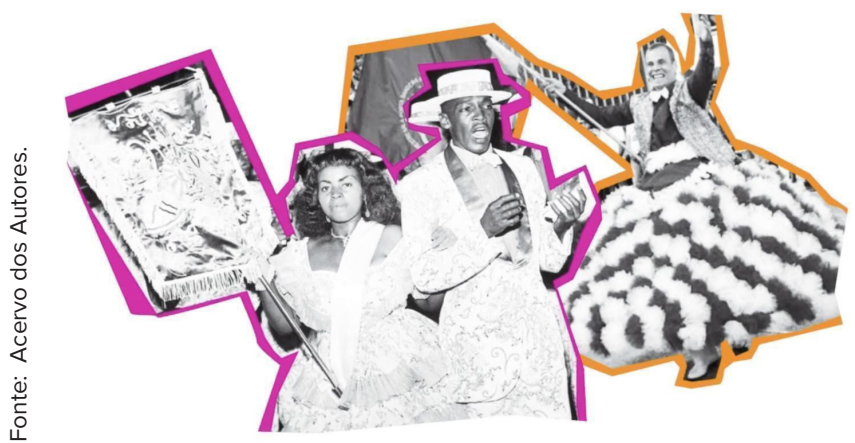

Figura 3. Uso de fotografia.

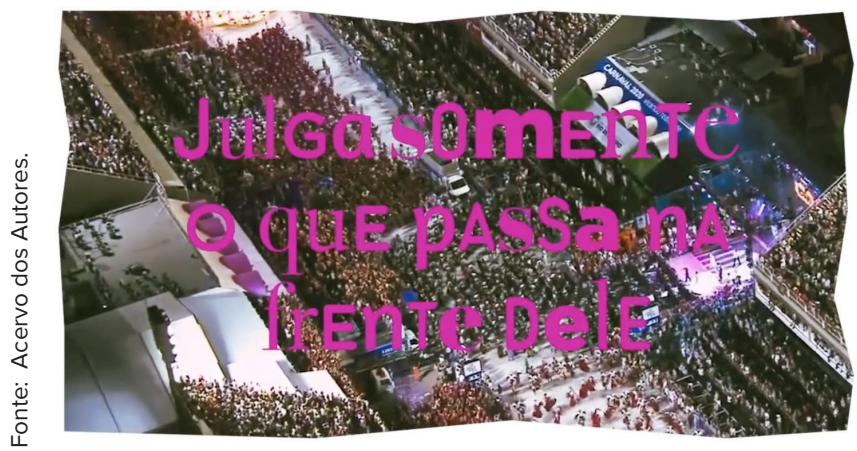

Figura 4. Aplicação tipográfica sob imagem.

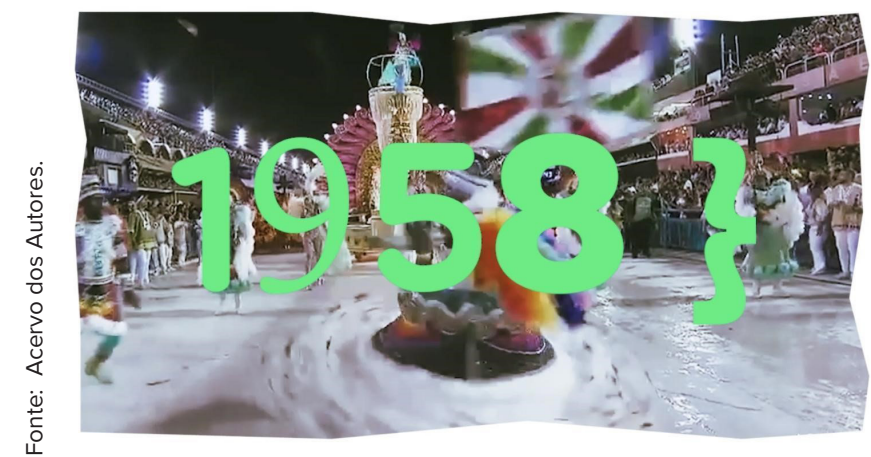

Figura 5. Aplicação tipográfica sob imagem.

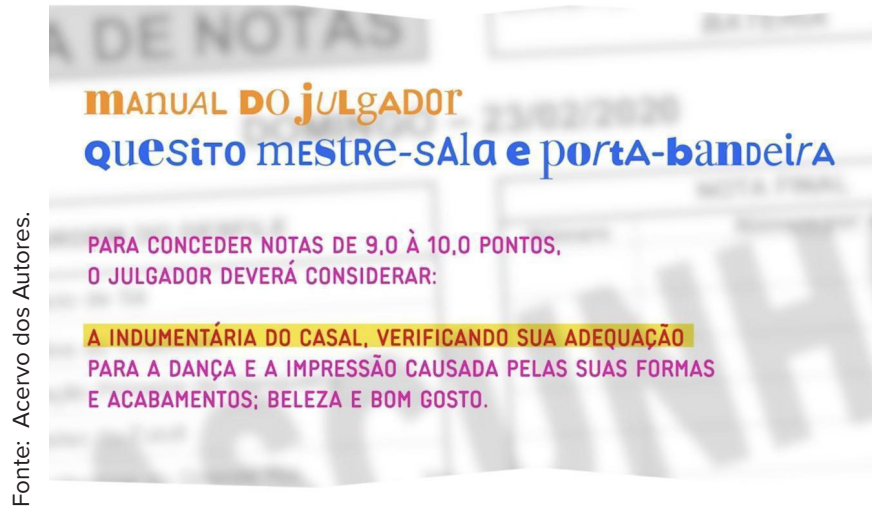

Figura 6. Aplicação tipográfica sob imagem.

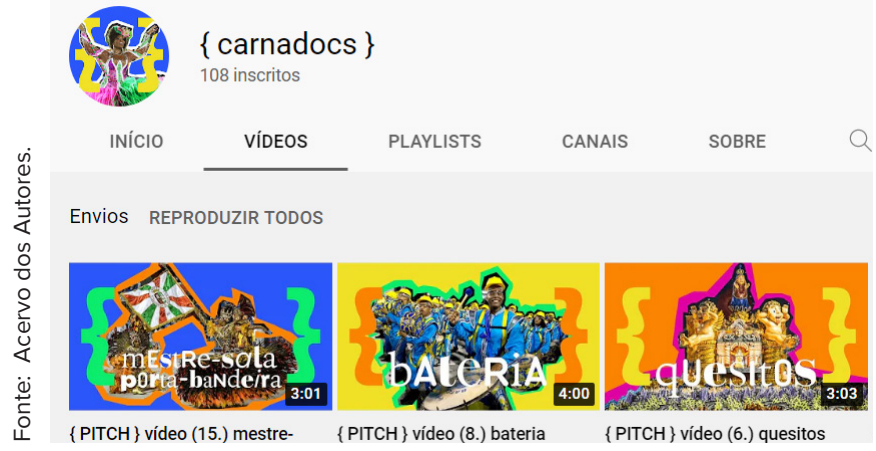

Figura 7. Thumbnails aplicadas em nosso canal do YouTube.

a um encaixe adequado que fosse fácil de animar, dimensionar e com liberdade para aplicabilidade em qualquer parte dos vídeos.

Inserções fotográficas foram necessárias para demarcar momentos históricos que não possuem acervo em vídeo. $\mathrm{Na}$ aplicação, percebemos que era necessário um tratamento para deixá-las em preto e branco e trazer a cor de outra forma. Inicialmente, a foto era usada em seu formato real e era contornada por linhas dançantes, porém essas atrapalhavam a assimilação da imagem e não tinha conexão com outros trechos animados do vídeo. Na versão adotada, as fotos ${ }^{5}$ surgem recortadas simulando aleatoriedade, mas preservando seu conteúdo e com uma borda de cor, recurso para mesclar a linguagem dos vídeos do desfile com os conteúdos produzidos pelo projeto, como ilustração, texto e fotografia, além de remeter a uma televisão transmitindo o desfile, mesmo que de forma irregular.

As inserções textuais são divididas em conteúdos curtos e extensos. Na primeira opção, faz-se obrigatório o uso das fontes tipográficas usadas no logotipo, com ordenação randômica, ajustando kerning e corpo mediante as alturas do

Revista online do Departamento de Arquitetura e Urbanismo da Pontifícia Universidade Católica do Rio de Janeiro - PUC-Rio, Brasil Ano 8 - No 9 - ISSN 2446-7340 
eixo x. Na segunda opção, deve-se usar somente a fonte Mini Tipo, ${ }^{6}$ permitindo melhor leitura.

Nos momentos em que é necessário utilizar mais de uma cena para ilustrar a informação do áudio, a tela é dividida em três partes na vertical com uma linha branca entre elas, de modo que todas tenham o mesmo peso. Em relação às transições, foram selecionadas as mais básicas, já presentes nos próprios softwares de edição. Além do corte seco, é permitido o uso de transição de cor, “divisão" e "empurrar”.

Os thumbnails, utilizados na divulgação dos vídeos, na plataforma do YouTube, ${ }^{7}$ contém imagens relativas aos quesitos, as chaves e o título do vídeo. A imagem deve seguir o padrão de recorte e borda sobre fundo chapado de cor.

\section{Seriação e produção colaborativa}

Para viabilizar o desenvolvimento futuro e completo da série, foi criado um manual de identidade visual com as referências, parâmetros e diretrizes para o desenvolvimento e implementação da série completa de vídeos, prevendo-se a atuação de outras equipes e profissionais em processos colaborativos. $^{8}$

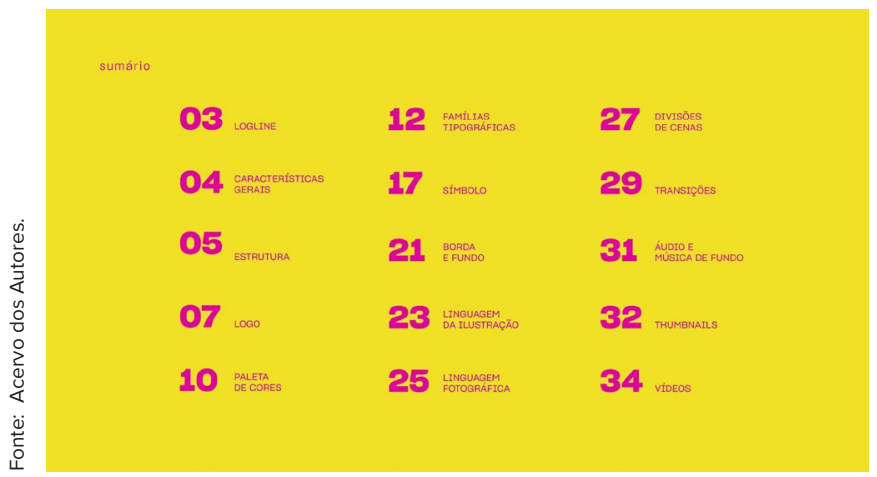

Figura 8. Sumário do Manual.

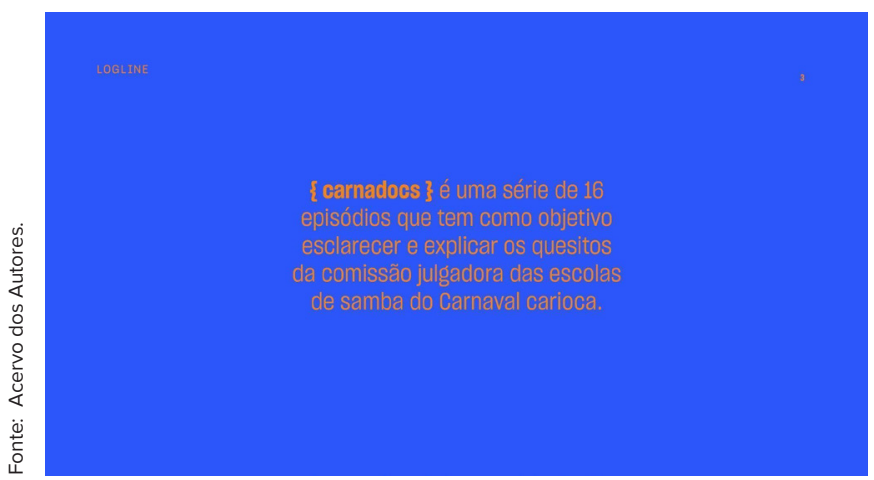

Figura 9.Sumário do Manual.

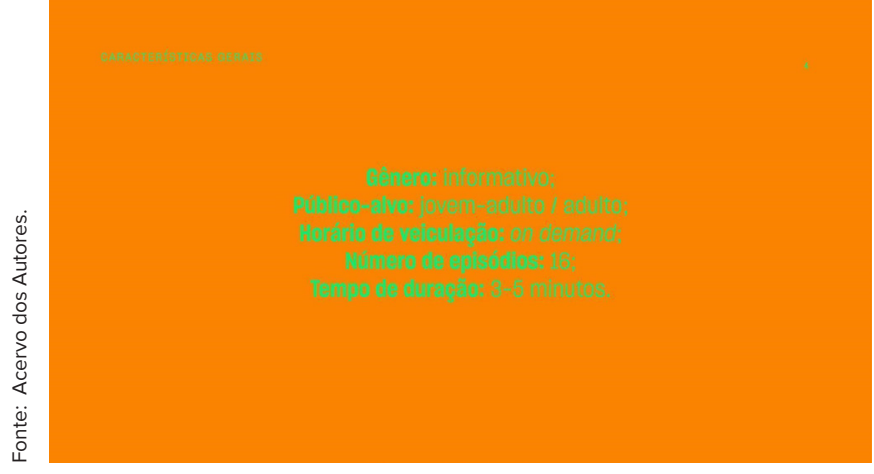

Figura 10. Sumário do Manual.

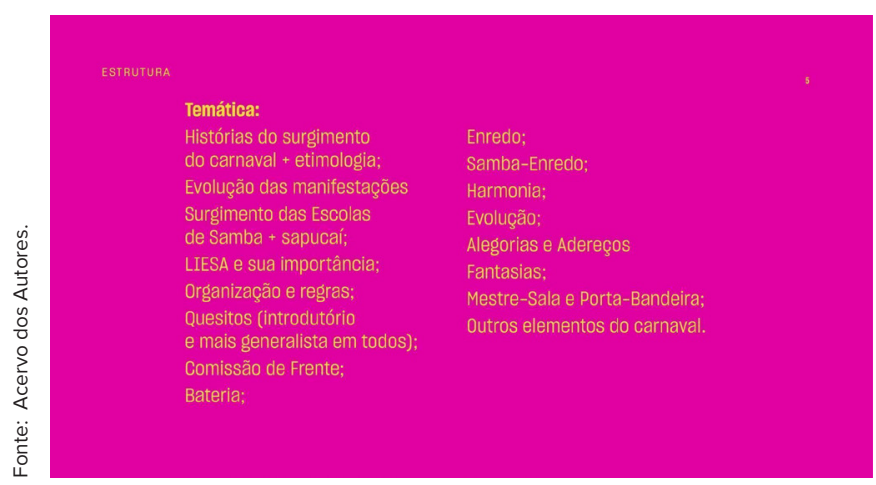

Figura 11. Sumário do Manual.

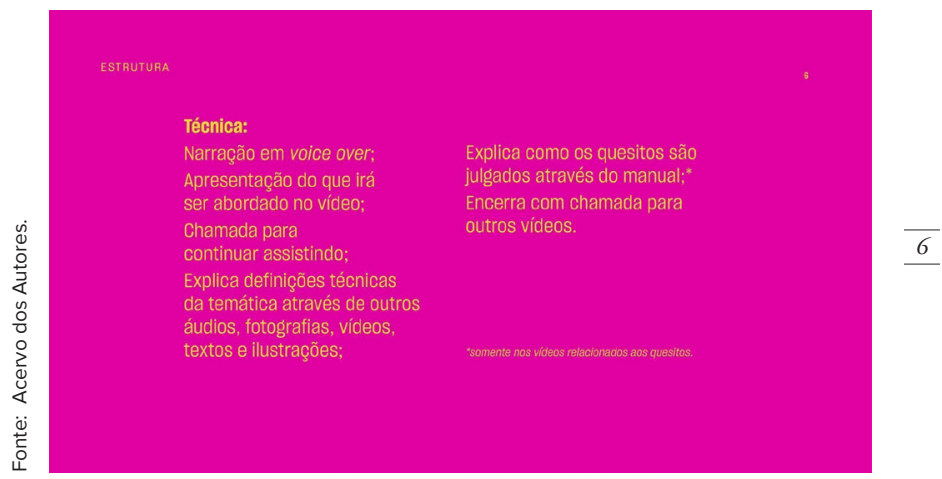

Figura 12. Sumário do Manual.

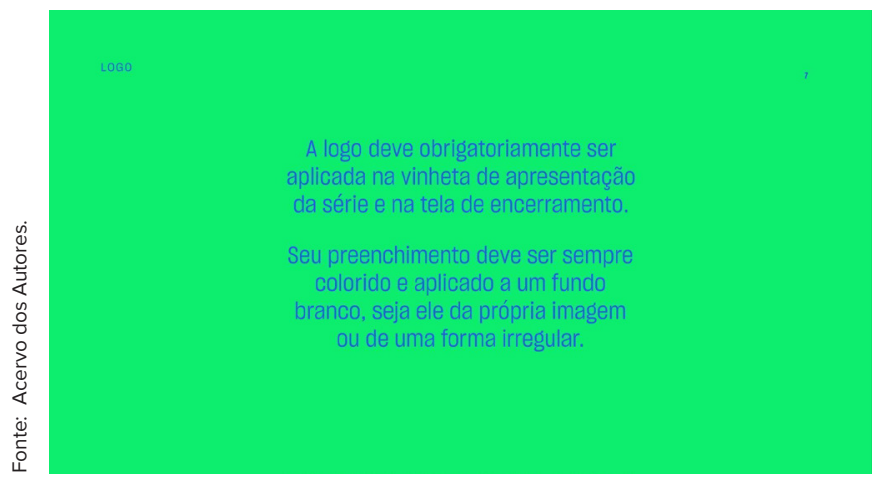

Figura 13. Sumário do Manual. 


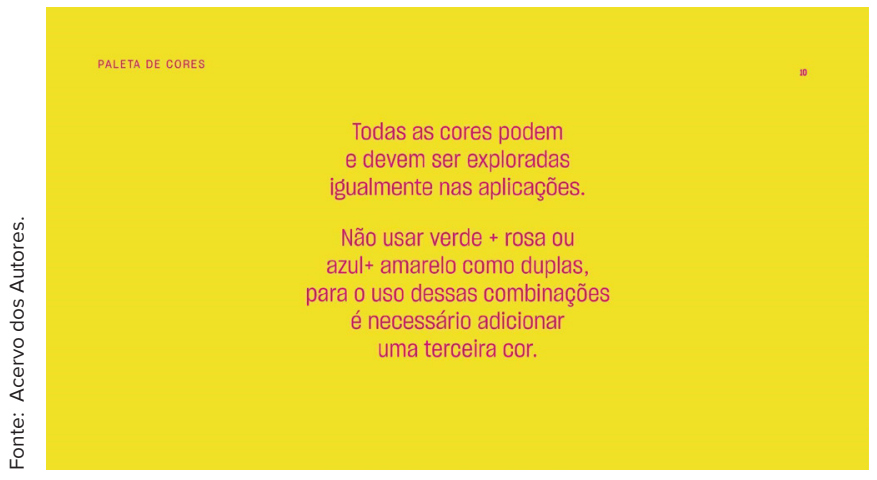

Figura 14. Sumário do Manual.

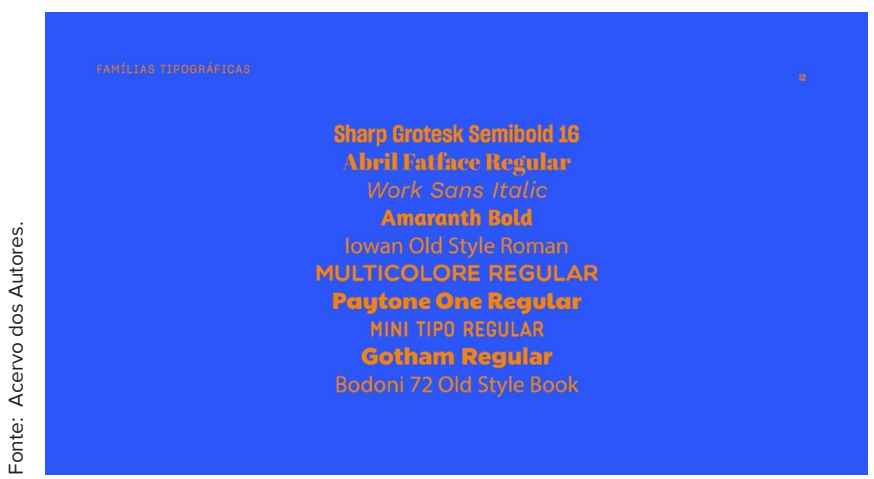

Figura 15. Sumário do Manual.

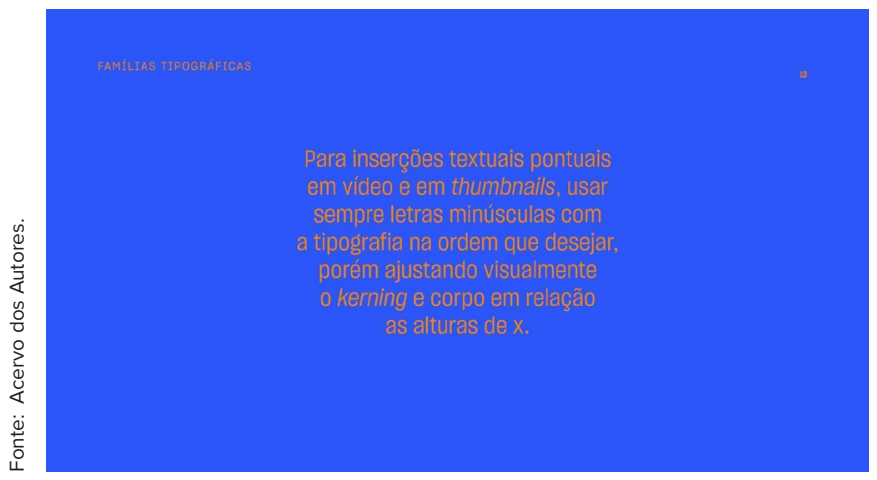

Figura 16. Sumário do Manual.

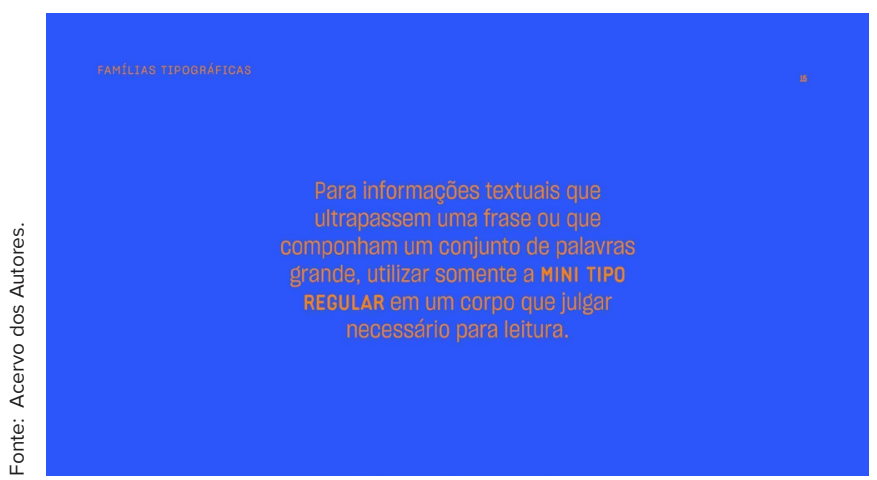

Figura 17.Sumário do Manual.

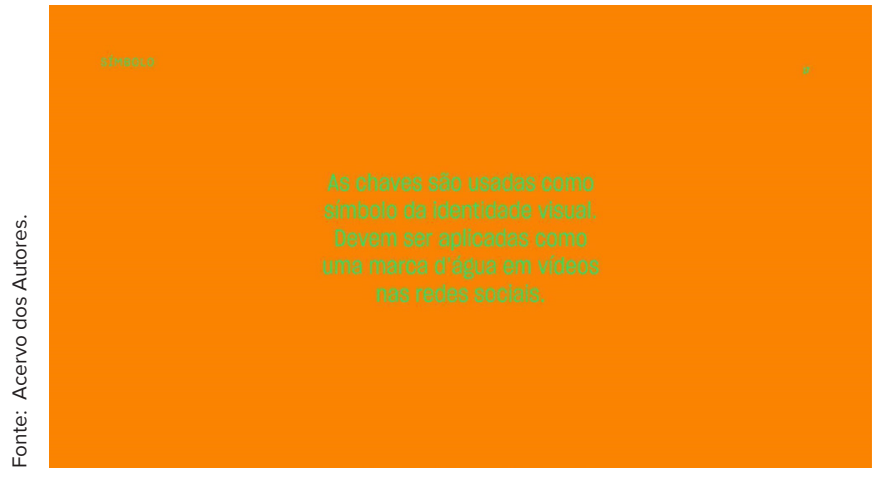

Figura 18. Sumário do Manual.

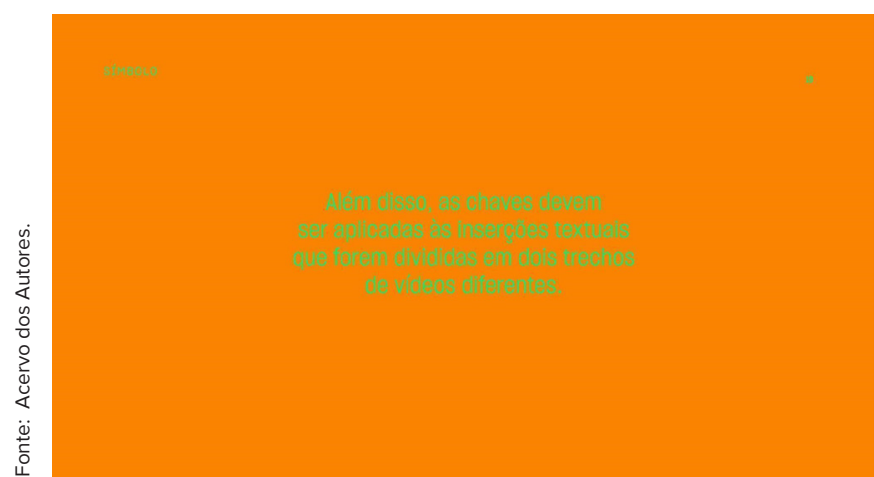

Figura 19. Sumário do Manual.

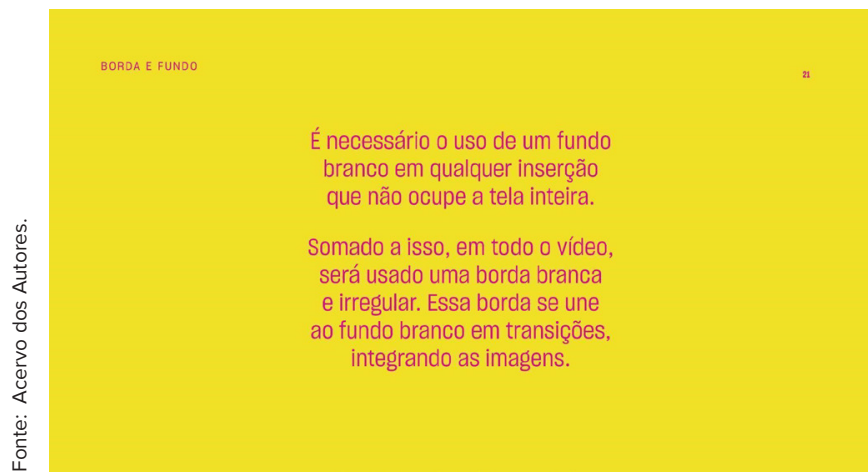

Figura 20. Sumário do Manual.

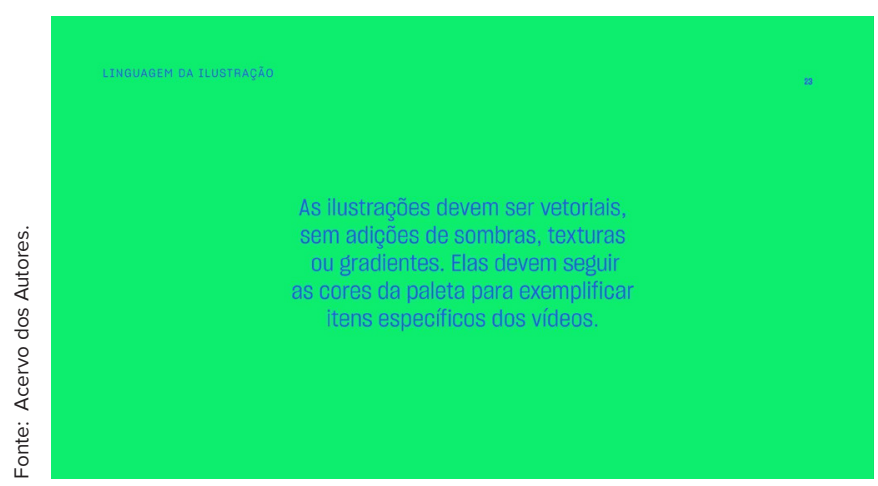

Figura 21. Sumário do Manual.

Revista online do Departamento de Arquitetura e Urbanismo da Pontifícia Universidade Católica do Rio de Janeiro - PUC-Rio, Brasil Ano 8 - No으 9 - ISSN 2446-7340 


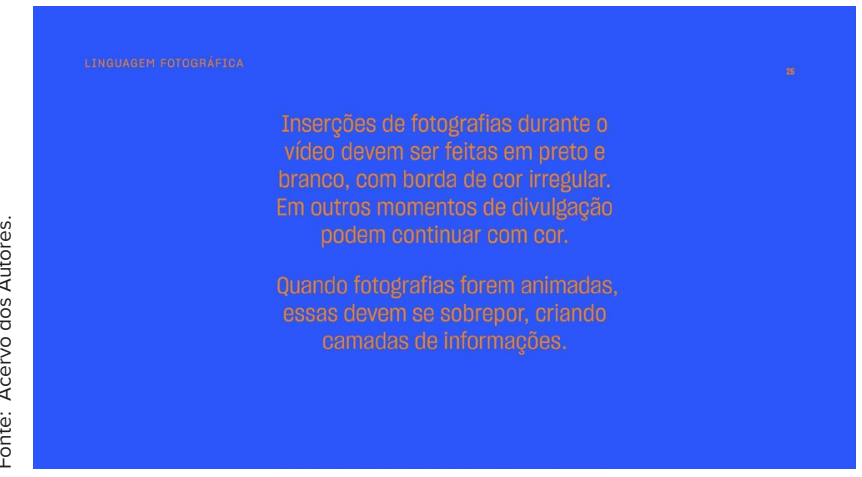

Figura 22. Sumário do Manual.

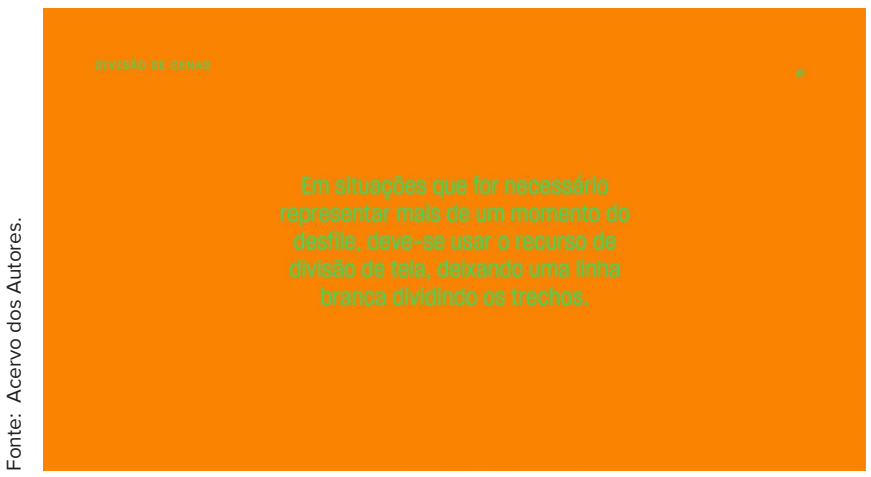

Figura 23. Sumário do Manual.

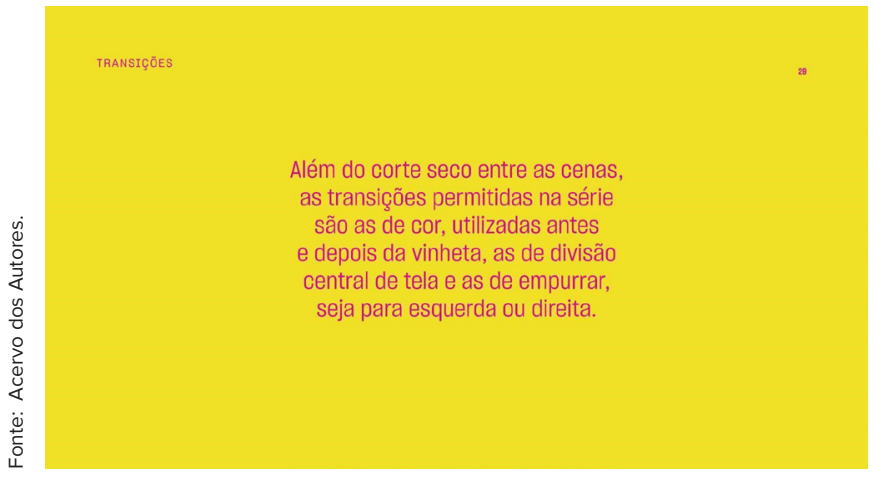

Figura 24. Sumário do Manual.

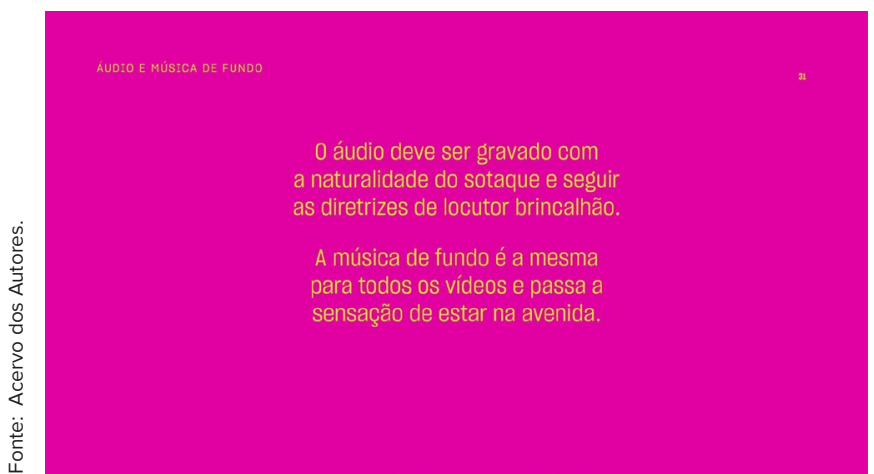

Figura 25. Sumário do Manual.
No manual, é possível perpassar todas as decisões visuais adotadas e compreendê-las a fim de reproduzi-las em outros conteúdos. Além disso, esse guia permite a busca de editais, crowdfunding e experiências de estruturas colaborativas para uma fase de validação.

\section{Conclusões}

A contribuição dos estudos de mídia no âmbito do Design para a ideia de sustentabilidade comunicacional é que a subárea de Comunicação Visual permite uma metodologia própria diante de conteúdos multissensoriais. Ao lidar com manifestações culturais populares vivas sem pretender uma abordagem museológica, mas de dialogar com o seu dinamismo social, sistemas multissensoriais podem preservar dados históricos, difundir informações sobre a contemporaneidade e propiciar uma processualidade que permita atualizações futuras. Uma manifestação que começa nas ruas de maneira marginal e se transforma em um espetáculo de expressão comercial e institucional tão consolidada, como os desfiles de escola de samba, é um ótimo exemplo da relevância da comunicação como forma de difusão socialmente responsável e sustentável para o evento.

A opção pelos quesitos selecionados para este projeto é fruto de um raciocínio de pesquisa que diagnostica as demandas particulares desse tema e consegue identificar sua relevância dentre uma série de possibilidades. A escolha e edição do conteúdo parte da extensão do tema e do valor de utilizar uma estrutura modular e trabalhar com focos e recortes. A identidade visual se detém na manutenção dos códigos materiais da própria manifestação ao criar novos elementos alheios ao desfile (logotipo, grafismos, ilustrações), embora baseados no evento. Além disso, organiza como esses elementos podem ajudar a comunicar imageticamente o festejo como um todo. Por fim, o manual de aplicação do sistema reúne e organiza as informações garantindo a operacionalidade de sua aplicação, consolidando um percurso fundamental para difusão responsável de um festejo complexo e de tão grande repercussão histórica, econômica, cultural e social. 


\section{Notas de fim:}

1. $\{$ carnadocs $\}$ é um projeto audiovisual desenvolvido durante a conclusão do curso de Nathália Valente em Comunicação Visual na Pontifícia Universidade Católica do Rio de Janeiro, apresentado à banca em dezembro de 2020

2. Via que liga os bairros de Madureira e Campos dos Afonsos no Rio de Janeiro. A partir de 1989 passou a ser um dos locais de desfiles de escolas de samba do carnaval carioca e assim mantém-se até hoje.

3. Desfile intitulado Guajupiá, terra sem males. De autoria dos carnavalescos Renato Lage e Márcia Lage, o tema retratava a história dos índios que habitavam a cidade do Rio de Janeiro bem antes da chegada dos portugueses, destacando a vida social, cultural, religiosa e política daqueles que são os primeiros "kariókas".

4. Para entender o processo de desenvolvimento, assistir: \{CARNADOCS $\}$. \{ teste 1$\}$ logo animada. 2020. Disponível em: https://www .youtube.com/watch?v=H49oRG8v_ho. Acesso em: 20, out. 2021; e \{CARNADOCS $\}$. \{ teste 2$\}$ logo animada. 2020. Disponível em: https://www.youtube.com/watch?v=JExHtPNKQnU. Acesso em: 20, out. 2021.

5. As fotografias utilizadas no pitch não se referem necessariamente às imagens reais que seriam usadas no projeto, elas servem apenas como simulação.

6. Tipografia desenvolvida pelo designer Fabio Lopez para o projeto Mini Rio. Saiba mais em: FABIO LOPEZ. mini Rio, [2018?]. Sobre / about. Disponível em: https://www.minirio.com.br/sobre--about .html. Acesso em: 20, out. 2020.

7. Para visualizar a produção completa: $\{$ CARNADOCS $\}$. Home. 2020. Canal na plataforma YouTube. Disponível em: www.youtube .com/c/carnadocs/. Acesso em: 20, out. 2021.

8. Para visualizar o manual completo: VALENTE, Nathália. \{ carnadocs \}: Manual de identidade visual. Disponível em: https://drive .google.com/file/d/1nT9MS6O2eYvkqeGvyWaKpa7FjyeiRy9p/view. Acesso em: 20, out. 2021.

\section{Referências bibliográficas}

AFP. No carnaval do Rio, guerra cultural surge em meio ao glitter. Isto $E$, 21, fev. 2020. Disponível em: https://istoe.com.br/no -carnaval-do-rio-guerra-cultural-surge-em-meio-ao-glitter/. Acesso em: 20, out. 2021.

GAMBA JUNIOR, Nilton G.; SARMENTO, Pedro. Sustentabilidade comunicacional: a realidade pós-editada. Estudos em Design, Rio de Janeiro, v. 27, n. 1, 2019. Disponível em: https://estudosemdesign .emnuvens.com.br/design/article/view/673. Acesso em: 04, mai. 2021

LIESA GLOBO. A LIESA. Disponível em: https:/liesa.globo .com/2018/por/o2-liesa/o2-liesa_principal.html. Acesso em: 25, abr. 2020

LIESA GLOBO. O manual do julgador do grupo especial da Liesa no Carnaval - 2020. Disponível em: http://liesa.globo.com/material /carnaval2o/julgador/Manual\%20do\%20Julgador-2020.pdf. Acesso em: 26, mar. 2020.

LIESA GLOBO. Regulamento especifico dos desfiles das escolas de samba do grupo especial da Liesa no Carnaval - 2020. Disponível em: https://liesa.globo.com/downloads/carnaval/regulamento-2020. pdf. Acesso em: 25, mar. 2020.

MOSS, Hugo. Como formatar seu roteiro. E-disciplinas USP, 1998. 15. Disponível em: https://edisciplinas.usp.br/pluginfile.php/4473939 /mod_resource/content/1/MOSS-Hugo-Como-formatar-seu -roteiro-copy.pdf. Acesso em: 20, abr. 2020.

SIMAS, Luiz Antonio; FABATO, Fábio. Pra tudo começar na quinta-feira: o enredo dos enredos. Rio de Janeiro: Mórula Editorial, 2015. 